\title{
Anterior crucial ligament rupture: self-healing through dynamic intraligamentary stabilization technique
}

\author{
Sandro Kohl • Dimitrios S. Evangelopoulos • \\ Hendrik Kohlhof • Max Hartel · Harald Bonel • \\ Phillip Henle • Brigitte von Rechenberg • Stefan Eggli
}

Received: 21 September 2011 / Accepted: 5 March 2012/Published online: 23 March 2012

(C) Springer-Verlag 2012

\begin{abstract}
Purpose Surgery involving arthroscopic reconstruction of the injured ligament is the gold standard treatment for torn anterior cruciate ligament (ACL). Recent studies support the hypothesis of biological self-healing of ruptured ACL. The aim of the study is to evaluate, in an animal model, the efficacy of a new technique, dynamic intraligamentary stabilization that utilizes biological self-healing for repair of acute ACL ruptures.

Methods The ACL in 11 adult female white alpine sheep was transected and in 8 sheep reconstructed by dynamic intraligamentary stabilization. To enhance the healing potential, microfracturing and collagen were used in all animals. The contralateral, non-operated knees served as controls. At 3 months postkilling, all animals were submitted to magnetic resonance imaging and biomechanical and histological evaluation.

Results No surgery-related complications were observed. Postoperatively, all animals regularly used the operated leg with full weight bearing and no lameness. At the time of killing, all animals exhibited radiological and histological
\end{abstract}

S. Kohl ( $₫)$ · D. S. Evangelopoulos · H. Kohlhof · M. Hartel ·

P. Henle $\cdot$ S. Eggli

Department of Orthopedic Surgery, Inselspital,

University of Bern, Freiburgstrasse, 3010 Bern, Switzerland

e-mail: Sandro.Kohl@Insel.ch

H. Bonel

Department of Radiology, Inselspital, University of Bern,

Bern, Switzerland

B. von Rechenberg

Equine Hospital, Vetsuisse Faculty, University of Zürich,

Zurich, Switzerland healing of the transacted ACL. Biomechanical tests confirmed successful restoration of anteroposterior translation in the dynamic intraligamentary stabilization knees. Histological examination revealed dense scar tissue at the ends of the transected ligaments exhibiting hypercellularity and hypervascularization.

Conclusion The dynamic intraligamentary stabilization technique successfully induced self-healing of ruptured ACL in a sheep model. Knee joints remained stable during the healing period allowing free range of motion and full weight bearing, and no signs of osteoarthritis or other intraarticular damage in the follow up were observed.

Keywords Anterior cruciate ligament rupture - Primary stabilization - Self-healing - Dynamic intraligamentary stabilization system

\section{Introduction}

It is well established that anterior cruciate ligament (ACL) insufficiency leads to symptomatic instability, secondary meniscal pathologies, and degenerative changes $[9,24,29]$. Both conservative and operative treatment choices are available. In case of low activity or old age, conservative treatment involving a muscle strengthening program and possible use of a brace may be indicated if overall knee stability is acceptable [3].

Among athletes, surgical treatment of the torn ACL with arthroscopic reconstruction of the injured ligament is the gold standard [37]. In this procedure the living structures of the ligament are removed and replaced with a biologically dead strand of ligament. A major disadvantage of using autologous materials, i.e. patellar or semitendinosus tendons, is donor-site morbidity and weakening of secondary 
knee stabilizers [2, 45, 46, 49]. As compared to healthy ACL, ACL transplants demonstrate a higher rupture rate, resulting in diminished stability of the knee joint. Synthetic materials, such as the Kennedy ligament augmentation device or the Trevira ligament, do not produce donor-site morbidity but they do have problems with long-term stability and biocompatibility. A disadvantage of all permanent materials is that they may create long-term stress shielding [11, 23, 31, 49, 51].

Recent studies support the hypothesis that ruptured ACL possesses a biological healing capacity [16, 42, 43, 47]. However, there is a dilemma associated with such healing; in order to obtain sufficient stability for ACL healing, 8 weeks of immobilization is required. Following such a lengthy period, the knee is likely to be stiff due to adhesions and ligamentous contractions [25].

To address this problem, we developed a new technique, dynamic intraligamentary stabilization (DIS), for the treatment of acute ACL ruptures. The DIS device combines an internal dynamic screw-spring mechanism with a $1.8-\mathrm{mm}$ braided polyethylene anchoring wire to provide continuous stability of the ACL and knee during the selfhealing period.

To test the efficacy of the technique, the self-healing capacity of the ruptured ACL following primary repair by DIS technique was evaluated in a sheep model through analysis of the macroscopic, histological and biomechanical reactions of the injured ligament treated with DIS technique.

\section{Materials and methods}

The animal experiment was conducted on adult female white alpine sheep according to Swiss national regulations for the care and use of laboratory animals. Prior to selection, all sheep were submitted to a knee X-ray and clinical examination to exclude possible pathologies or sickness that could interfere with the study. Knees with degenerative lesions according to the Kelgreen and Lawrence classification (>grade 0 ) or with ligamentous instability were excluded from the study [20].

Eleven adult female white alpine sheep (average age 3 years, average weight $74 \mathrm{~kg}$, range $66-98 \mathrm{~kg}$ ) fulfilled the selection criteria and were included in the study. All animals were subjected to transection of the ACL. Eight sheep composed the study group and received treatment with DIS device, microfracturing and collagen, while 3 sheep were used as a second control group and were treated only with microfracturing and a collagen sheath.

Postkilling, all animals were submitted to histological and biomechanical testing as well as to magnetic resonance imaging (MRI) of the knees.
Dynamic intraligamentary stabilization: rationale and surgical technique

The DIS device is designed to stabilize the knee joint during the self-healing period, holding the knee in constant posterior translation in every position of flexion. It consists of a threaded sleeve $(10 \times 25 \mathrm{~mm})$ housing a preloaded spring and a mechanism for securing the spring in the tibia. A braided wire $(1.8 \mathrm{~mm})$ traverses the knee joint through the middle of the torn ACL, exiting through the lateral aspect of the femur where it is anchored with a button to the bone. The preloaded spring serves to keep the knee in a posterior drawer, thus holding the two torn anterior cruciate ligament ends together to allow healing of the ACL at its original length without loss of stability (Fig. 1).

\section{Surgical technique}

The anesthetized sheep is placed in dorsolateral recumbency with the limb to be operated on in flexion and at a $90^{\circ}$ angle to the surgery table and the ACL is cut close to the femoral insertion through a minimally invasive medial arthrotomy.

After performing microfractures at the femoral footprint, a k-wire is drilled simulating the physiological course of the ACL from the anteromedial aspect of the tibia (tibial footprint) through the ACL to the posterolateral notch of the femur (femoral footprint). The threaded sleeve is then implanted in the tibial side. The $1.8-\mathrm{mm}$ braided wire is next inserted through the drilled canal and fixed at the femoral side with a button and at the tibial side with an intraosseous spring-loaded screw with a preload of $85 \mathrm{~N}$.

In all animals of the DIS group, the two ACL ends were covered with a collagen membrane (Chondro-Guide, Geistlich Ltd, Wolhusen, Switzerland) to enhance healing potential. Postoperatively, all operated animals were allowed free mobilization with full weight bearing and free range of motion.

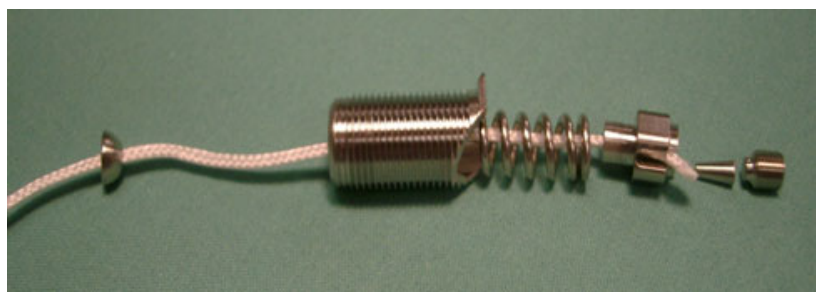

Fig. 1 The DIS device consisting of a threaded sleeve $(10 \times 25 \mathrm{~mm})$ housing a preloaded spring, a metal anchor for securing the braided wire on the tibial side, and a metal button to secure the femur side 
Radiological evaluation

All sheep were killed 3 months postoperatively. The femur and tibia were dissected approximately $15 \mathrm{~cm}$ from the joint space and all knees were examined in an advanced 3 Tesla scanner (Trio TIM, Siemens Medical Systems, Erlangen, Germany) using a 15-channel phased-array knee coil. Proton density-weighted images were acquired in parasagittal planes perpendicular to the posterior condyles as depicted in axial scout planes using a 3D steady-state gradient-echo sequence. Measurement time lasted 7:04 min and the specific absorption rate complied with EU and FDA standards. MRI signal was rated using the Howell grading system [18].

Mechanical tests

The muscular attachments to the tibia and the femur, the patellar tendon and the joint capsule were removed, leaving the collateral and cruciate ligaments intact.

AP laxity tests were performed using a standard materials testing system (Zwick 1475, Ulm, Germany). The femoral support was directly connected to the actuator of the test system and the knee was positioned at $60^{\circ}$ of flexion to simulate the anterior drawer. The femur was supported on a 3D platform allowing unconstrained axial rotation and translation in the coronal and sagittal planes. The tibia was supported on a fixed platform enabling the knee joint to maintain a constant proper neutral position throughout the biomechanical testing. AP laxity was defined as a total AP displacement between the AP shear load limits of $-10 \mathrm{~N}$ to $+60 \mathrm{~N}$. The AP loads and displacements were directly measured from the load cell (resolution $<0.1 \mathrm{~N}$ ) and linear variable differential transformer (resolution $0.14 \mathrm{~mm}$ ) of the materials testing system. The shear loads were directly applied to the femur via the materials testing system. To be consistent with clinical standards, laxity values were reported as the displacement of the femur relative to the fixed tibia. AP displacements were measured for three cycles of the applied shear. The average displacement of these three cycles was used as the total AP laxity value.

\section{Histological examination}

The ACL was excised leaving a $2-\mathrm{cm}^{3}$ bone block from the femoral and tibial insertion sites attached to the ligament. The specimens were then dehydrated by graded ethanol, fixed in formalin, embedded in methylmethacrylate and cut into representative $2 \mu \mathrm{m}$ sagittal sections. The sections were then stained with toluidine blue and Goldner's trichrome technique for investigation by light microscopy.
Statistical analysis

Statistical analysis was performed by the paired two-sample Student's $t$ test with a significance level of $5 \%$ $(p=0.05)$. Histology and MRI findings were evaluated by descriptive analysis.

\section{Results}

No complications related to the surgical procedure occurred in the postoperative course. All animals recovered well from surgery and after a maximum of 3 days all animals of the DIS group showed no lameness and used the operated leg regularly with full weight bearing. At the time of killing, all animals were walking normally. The number of control animals is limited for ethical reasons, since postoperatively the animals demonstrated rapid deterioration of the joint, excessive limping and were unable to walk.

\section{Radiological evaluation}

MRI quality was rated as optimal (score 5) in five sheep and very good (score 4) in three sheep at 3 months. Continuity was rated grade $\mathrm{A}$, or 'well defined', in eight sheep. All repairs were well defined and ligament continuity was fully restored. Applying the Howell grading system, MRI signals were rated grade I in five of the eight sheep after 3 months and grade II in the remaining three sheep.

The cross-sectional area of the transected ligaments, treated with collagen and microfracturing, did not differ from that of the healthy ACL. No cartilaginous or meniscal lesions were encountered. A discrete signal alteration was observed around the braided wire in the tibial bone (Fig. 2).

\section{Mechanical tests}

The DIS technique restored AP stability in all operated knees. Intact knees had an average AP laxity of $1.1 \mathrm{~mm}$ (range $0.8-1.5 \mathrm{~mm}$ ) and a stiffness of $48.7 \mathrm{~N} / \mathrm{mm}$ (range 41.3-57.8/N/mm). DIS-stabilized knees exhibited an average AP laxity of $2.5 \mathrm{~mm}$ (range $1.7-3.3 \mathrm{~mm}$ ) and a stiffness of $31.1 \mathrm{~N} / \mathrm{mm}$ (range 27.4-36.2 N/mm). For lower forces $(20 \mathrm{~N})$, DIS ACL demonstrated a higher translation than control ACL. At higher forces $(60 \mathrm{~N})$, however, no difference in translation was observed between DIS ACL and control ACL (Fig. 3). For all measurements average AP translation values for DIS ACL were $1.4 \mathrm{~mm}$ higher than those for intact ligaments, 

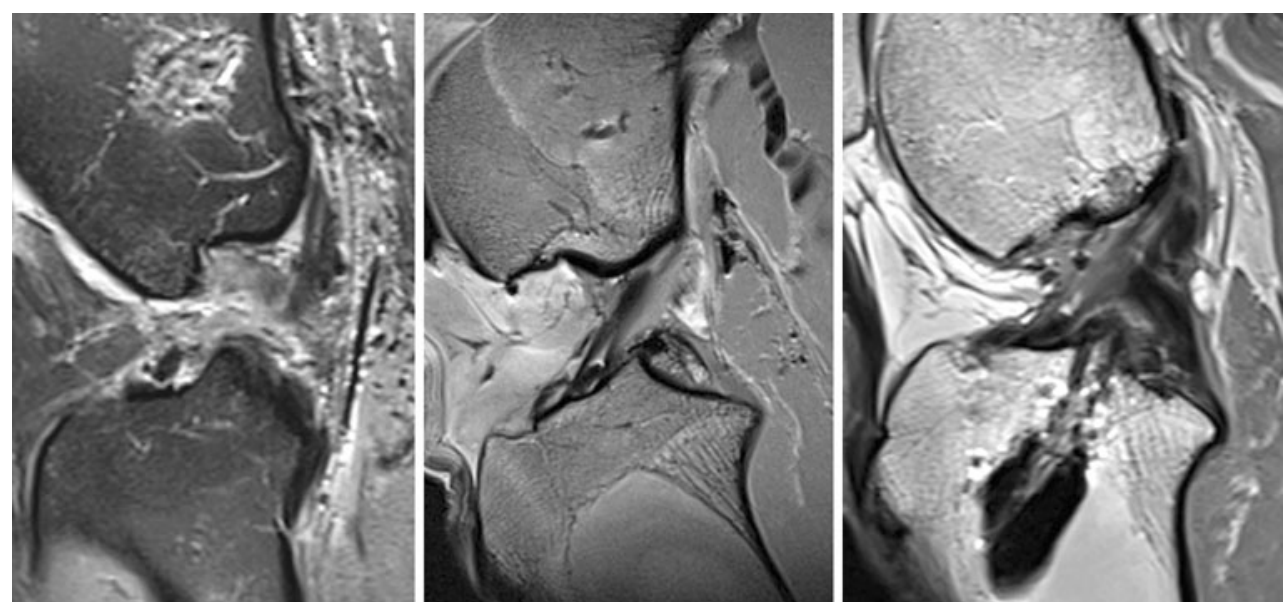

Fig. 2 Left No scar tissue is visible in a control knee 3 months after ACL transection without DIS stabilization. Middle Normal ACL. Right The DIS primary stabilization of the ruptured ACL after 3 months

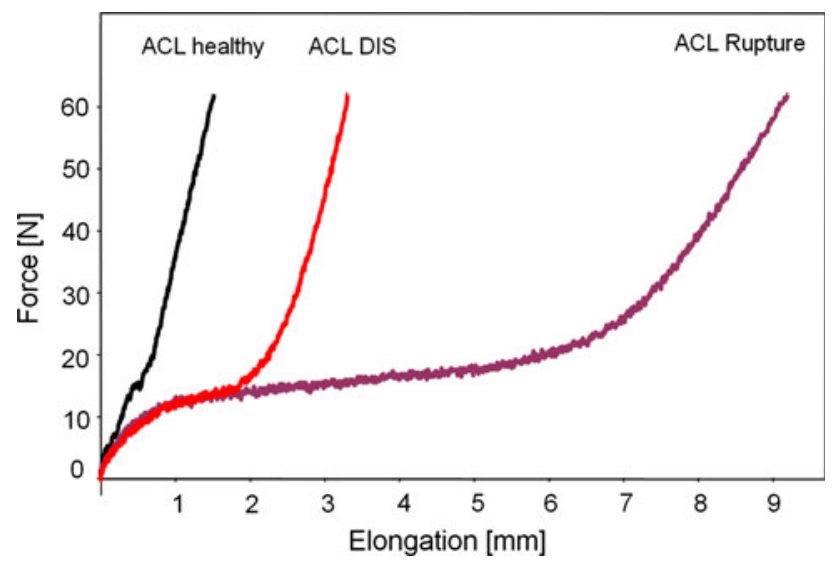

Fig. 3 AP laxity of healthy ACL, DIS-repaired ACL (after 3 months of self-healing), and ruptured ACL establishing and maintaining close contact between the two ends of the ruptured ACL and ensuring optimal conditions for healing.

\section{Histological investigations}

Macroscopically, all repaired ACLs appeared healed (Fig. 4). Histological analysis of the representative sagittal sections showed that the scar mass at the ends of the transected ligaments exhibited hypercellularity and hypervascularization after 3 months. The vast majority of cells within the scar mass were fibroblasts, with only rare inflammatory cells. The distal tibial remnant of the transected ACL appeared to be covered anteriorly with a hypertrophic tissue that was continuous with the anterior
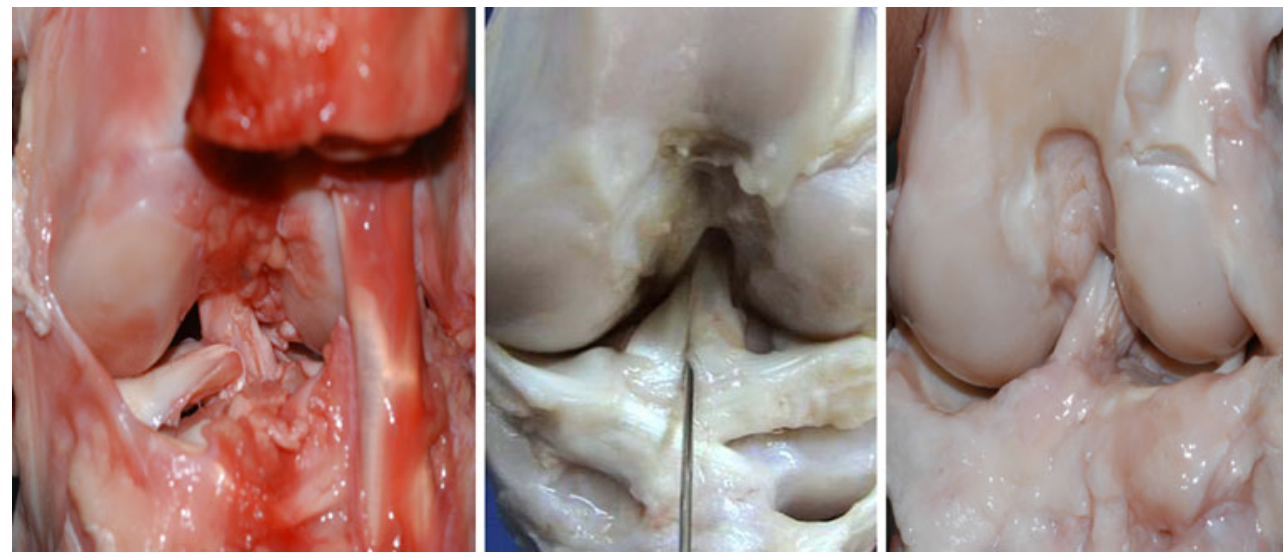

Fig. 4 Macroscopic images. Left (direct view of PCL) 3 months after ACL transection without DIS stabilization there is no ACL healing, dislocation of the medial meniscus, and cartilage degeneration on the medial femoral condyle. Middle Normal ACL. Right ACL healing 3 months after transection and primary stabilization by DIS; no cartilage degeneration or meniscus lesion 


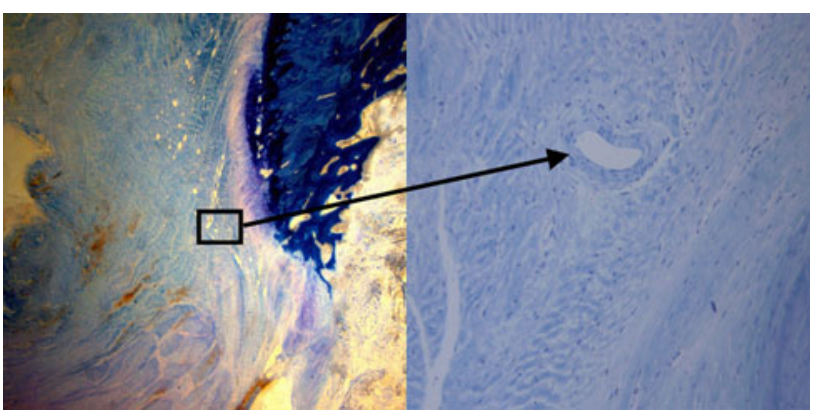

Fig. 5 Histological analysis at 3 months. Left Dense tissue at the ruptured ends of the ACL. Right Hypercelluarity and neovascularization of the dense connective tissue

fat pad, extending to the ACL wound site. In addition, the ACL remnants contained areas of hypertrophic epiligamentous tissue between fascicles (Fig. 5).

\section{Discussion}

The most important finding of the present study was that the DIS technique provided adequate AP stability for the healing of the ruptured ACL in a sheep model.

Recent innovations in ACL repair, including the doublebundle technique, have produced improved biomechanical 3D stability for ACL reconstruction [40, 45]. However, most significant problems remain unsolved, including pain at the graft harvest site, loss of proprioception, increasing osteoarthritis, and changes in graft anatomy resulting in elongation and gradual loosening [6, 8, 13, 21, 27, 28, 34].

A surgical technique that exploits the ACL's physical propensity for self-healing would possess serious advantages over the classic arthroscopic technique with regard to operation time, postoperative swelling and pain, functional problems at the harvest site, maintenance of proprioception, and duration of the rehabilitation period $[4,51]$.

The low success rate of the primary suturing technique, as described by Marshal, can be attributed to both biological and mechanical factors [29]. Compared to the MCL, the ACL has poor healing capacity which is mainly attributed to its lower cellular proliferation and migration potential $[22,41,50]$. Since growth factors mediate ligament cell proliferation, techniques such as microfracturing or addition of plasma reach factors (PRF) could locally increase chemotaxis and mitogenesis and act beneficially on ACL healing potential $[5,12,35,42]$.

Biomechanically, the knee shows a coupled flexiontranslation-rotation motion pattern, which increases the distance between the two ends of the ruptured ACL, thus impairing the physiological healing process [39]. In the present study, mechanical tests showed that the DIS technique successfully restores normal AP stability of sheep knees at all angles of flexion, thus facilitating healing of the sutured ACL, especially during the crucial early period [17]. Although the results of DIS ACL initially demonstrated a higher translation than control ACL for lower forces $(20 \mathrm{~N})$, no such difference was observed at higher forces $(60 \mathrm{~N})$ (Fig. 3). Average AP translation values for DIS ACL were $1.4 \mathrm{~mm}$ higher than those for intact ligaments, establishing and maintaining close contact between the two ends of the ruptured ACL and ensuring optimal conditions for healing. In contrast, the results in control animals receiving only microfracturing and a collagen sheath were devastating, with rapid deterioration of the joint, excessive limping and inability to walk.

DIS resulted in a stable healing of the injured ligament as shown by MRI and histological analysis. MRI has been successfully used in the past to evaluate healing progression. In a study on conservative ACL healing, Ihara et al. [19] reported that MRI assessment of the ACL at 3-month follow-up depicted a well-defined normal-sized straight band. In the present study, the signal intensity ranged from optimal to very good and ligament continuity was fully restored on the MRI sequences. Mastrangelo et al. [32], in their study on the healing of experimentally transected animal ACL, found, at 4-week follow-up, significant fibroblastic proliferation, formation of large arterioles with multicellular cell wall layers and the presence of collagen fibers aligned parallel with the fibroblasts, arranged along the length of the axis of the healing ligament. We report similar histological features in the present study. In addition, the dense connective tissue and marked neovascularization detected on histological analysis attest to the excellent self-healing potential of the DIS-ACL.

The DIS permits fast primary repair of the injured ACL exploiting physiological healing process and avoiding major complications of the classical reconstruction techniques such as donor-site morbidity and weakening of secondary knee stabilizers. The technique itself is minimally invasive, further facilitating potential healing. The tibial drilling for implantation of the spring-loaded screw remains completely extraarticular, thereby preserving the original femoral and tibial ACL insertions with the blood supply for the ACL. Apart from the 1.8-mm braided intraligamentary wire, no other material obstructs the ACL's vital space during the healing process. Moreover, the limited diameter of our stabilizing wire enables the introduction of a biological scaffold to promote the physiological healing process at the site of the injured ligament. Further enhancement of the healing potential can be achieved through microfracturing or other techniques such as collagen adhesion and plasma reach factors (PRF) [14, 44].

Despite our efforts to ensure the reliability of this study, it does have certain limitations. Although animal studies, mainly on dogs and sheep, suggest that killing after 
3 months allows sufficient time to document degenerative joint lesions, it should be borne in mind that only chondromalacia or early osteoarthritic changes are observed during this period $[15,26,36,38]$. Moreover, since the present study employed an animal model, the ACL was fully transected by means of a transverse cut. The mechanism of the experimental lesions, therefore, could not reproduce the actual conditions of human ACL rupture that include violent fiber elongation and distraction.

\section{Conclusions}

The present findings show that the DIS technique provides the primary stability necessary for healing of the ACL following rupture and can successfully restore AP laxity of the knee.

\section{References}

1. Abramowitch SD, Papageorgiou CD, Withrow JD, Gilbert TW, Woo SL (2003) The effect of initial graft tension on the biomechanical properties of a healing ACL replacement graft: a study in goats. J Orthop Res 21:708-715

2. Aglietti P, Giron F, Buzzi R, Biddau F, Sasso F (2004) Anterior cruciate ligament reconstruction: bone-patellar tendon-bone compared with double semitendinosus and gracilis tendon grafts-a prospective, randomized clinical trial. J Bone Joint Surg Am 86:2143-2155

3. Ahn JH, Chang MJ, Lee YS, Koh KH, Park YS, Eun SS (2010) Non-operative treatment of ACL ruptures with mild instability. Arch Orthop Trauma Surg 130:1001-1006

4. Amiel D, Frank C, Harwood F, Fronek J, Akeson W (1984) Tendons and ligaments: a morphological and biochemical comparison. J Orthop Res 1:257-265

5. Amiel D, Nagineni CN, Choi SH, Lee J (1995) Intrinsic properties of ACL and MCL cells and their responses to growth factors. Med Sci Sports Exerc 27:844-851

6. Biau DJ, Tournoux C, Katsahian S, Schranz PJ, Nizard RS (2006) Bone-patellar tendon-bone autografts versus hamstring autografts for reconstruction of anterior cruciate ligament: meta-analysis. BMJ 332:995-1001

7. Biau DJ, Katsahian S, Nizard R (2007) Hamstring tendon autograft better than bone-patellar tendon-bone autograft in ACL reconstruction - a cumulative meta-analysis and clinically relevant sensitivity analysis applied to a previously published analysis. Acta Orthop 78:705-707

8. Maak TG, Bedi A, Raphael BS, Citak M, Suero EM, Wickiewicz T, Pearle AD (2011) Effect of femoral socket position on graft impingement after anterior cruciate ligament reconstruction. Am J Sports Med 39:1018-1023

9. Crema MD, Marra MD, Guermazi A, Bohndorf K, Roemer FW (2009) Relevant traumatic injury of the knee joint-MRI followup after 7-10 years. Eur J Radiol 72:473-479

10. Cummings JF, Grood ES (2002) The progression of anterior translation after anterior cruciate ligament reconstruction in a caprine model. J Orthop Res 20:1003-1008

11. Dahlstedt L, Dalén N, Jonsson U (1990) Goretex prosthetic ligament vs. Kennedy ligament augmentation device in anterior cruciate ligament reconstruction. A prospective randomized 3-year follow-up of 41 cases. Acta Orthop Scand 61:217-224

12. Date H, Furumatsu T, Sakoma Y, Yoshida A, Hayashi Y, Abe N, Ozaki T (2010) GDF-5/7 and Bfgf activate integrin alpha2mediated cellular migration in rabbit ligament fibroblasts. J Orthop Res 28:225-231

13. Etchepareborde S, Brunel L, Bollen G, Balligand M (2011) Preliminary experience of a modified Maquet technique for repair of cranial cruciate ligament rupture in dogs. Vet Comp Orthop Traumatol 24:223-227

14. Fallouh L, Nakagawa K, Sasho T, Arai M, Kitahara S, Wada Y, Moriya H, Takahashi K (2010) Effects of autologous platelet-rich plasma on cell viability and collagen synthesis in injured human anterior cruciate ligament. J Bone Joint Surg Am 92:2909-2916

15. Fernandes JC, Jovanovic D, Dehnade F, Martel-Pelletier J, Pelletier JP (1998) Resection of the anterior cruciate ligament of the knee using arthroscopy induces arthrosis in dogs. Validity of the Pond-Nuki model. Ann Chir 52:768-775

16. Fleming BC, Carey JL, Spindler KP, Murray MM (2008) Can suture repair of ACL transection restore normal anteroposterior laxity of the knee? An ex vivo study. J Orthop Res 26:1500-1505

17. Frobell RB, Le Graverand MP, Buck R, Roos EM, Roos HP, Tamez-Pena J, Totterman S, Lohmander LS (2009) The acutely ACL injured knee assessed by MRI: changes in joint fluid, bone marrow lesions, and cartilage during the first year. Osteoarthr Cartilage 17:161-167

18. Howell SM, Clark JA, Farley TE (1992) Serial magnetic resonance study assessing the effects of impingement on the MR image of the patellar tendon graft. Arthroscopy 8:350-358

19. Ihara H, Miwa M, Deya K, Torisu K (1996) MRI of anterior cruciate ligament healing. J Comput Assist Tomogr 20:317-321

20. Kellgren JH, Lawrence JS (1957) Radiological assessment of osteoarthrosis. Ann Rheum Dis 16:494-502

21. Kessler MA, Behrend H, Henz S, Stutz G, Rukavina A, Kuster MS (2008) Function, osteoarthritis and activity after ACL-rupture: 11 years follow-up results of conservative versus reconstructive treatment. Knee Surg Sports Traumatol Arthrosc $16: 442-448$

22. Kobayashi K, Healey RM, Sah RL, Clark JJ, Tu BP, Goomer RS, Akeson WH, Moriya H, Amiel D (2000) Novel method for the quantitative assessment of cell migration: a study on the motility of rabbit anterior cruciate (ACL) and medial collateral ligament (MCL) cells. Tissue Eng 6:29-38

23. Krych AJ, Jackson JD, Hoskin TL, Dahm DL (2008) A metaanalysis of patellar tendon autograft versus patellar tendon allograft in anterior cruciate ligament reconstruction. Arthroscopy 24:292-298

24. Krych AJ, Pitts RT, Dajani KA, Stuart MJ, Levy BA, Dahm DL (2010) Surgical repair of meniscal tears with concomitant anterior cruciate ligament reconstruction in patients 18 years and younger. Am J Sports Med 38:976-982

25. Lee S, Sakurai T, Ohsako M, Saura R, Hatta H, Atomi Y (2010) Tissue stiffness induced by prolonged immobilization of the rat knee joint and relevance of AGEs (pentosidine). Connect Tissue Res 51:467-477

26. Libicher M, Ivancic M, Hoffmann M, Wenz W (2005) Early changes in experimental osteoarthritis using the Pond-Nuki dog model: technical procedure and initial results of in vivo MR imaging. Eur Radiol 15:390-394

27. Lidén M, Sernert N, Rostgård-Christensen L, Kartus C, Ejerhed L (2008) Osteoarthritic changes after anterior cruciate ligament reconstruction using bone-patellar tendon-bone or hamstring tendon autografts: a retrospective, 7-year radiographic and clinical follow-up study. Arthroscopy 24:899-908

28. Lohmander LS, Ostenberg A, Englund M, Roos H (2004) High prevalence of knee osteoarthritis, pain, and functional limitations 
in female soccer players twelve years after anterior cruciate ligament injury. Arthritis Rheum 50:3145-3152

29. Louboutin H, Debarge R, Richou J, Selmi TA, Donell ST, Neyret P, Dubrana F (2009) Osteoarthritis in patients with anterior cruciate ligament rupture: a review of risk factors. Knee 16:239-244

30. Marshall JL, Warren RF, Wickiewicz TL, Reider B (1979) The anterior cruciate ligament: a technique of repair and reconstruction. Clin Orthop Relat Res 143:97-106

31. Mascarenhas R, MacDonald PB (2008) Anterior cruciate ligament reconstruction: a look at prosthetics-past, present and possible future. Mcgill J Med 11:29-37

32. Mastrangelo AN, Haus BM, Vavken P, Palmer MP, Machan JT, Murray MM (2010) Immature animals have higher cellular density in the healing anterior cruciate ligament than adolescent or adult animals. J Orthop Res 28:1100-1106

33. Mayr HO, Stoehr A, Dietrich M, von Eisenhart-Rothe R, Hube R, Senger S, Suedkamp NP, Bernstein A (2011) Graft-dependent differences in the ligamentization process of anterior cruciate ligament grafts in a sheep trial. Knee Surg Sports Traumatol Arthrosc. doi:10.1007/s00167-011-1678-7

34. Muaidi QI, Nicholson LL, Refshauge KM, Adams RD, Roe JP (2009) Effect of anterior cruciate ligament injury and reconstruction on proprioceptive acuity of knee rotation in the transverse plane. Am J Sports Med 37:1618-1626

35. Murray MM (2009) Current status and potential of primary ACL repair. Clin Sports Med 28:51-61

36. Pritzker KP (1994) Animal models for osteoarthritis: processes, problems and prospects. Ann Rheum Dis 53:406-420

37. Radice F, Yánez R, Gutiérrez V, Rosales J, Pinedo M, Coda S (2010) Comparison of magnetic resonance imaging findings in anterior cruciate ligament grafts with and without autologous platelet-derived growth factors. Arthroscopy 26:50-57

38. Richter M, Durselen L, Ignatius A, Missler F, Claes L, Kiefer H (1997) Acutely repaired proximal anterior cruciate ligament ruptures in sheep-by augmentation improved stability and reduction of cartilage damage. J Mater Sci Mater Med 8:855-859

39. Shelburne KB, Pandy MG, Torry MR (2004) Comparison of shear forces and ligament loading in the healthy and ACL-deficient knee during gait. J Biomech 37:313-319

40. Siebold R, Dehler C, Ellert T (2008) Prospective randomized comparison of double-bundle versus single-bundle anterior cruciate ligament reconstruction. Arthroscopy 24:137-145
41. Wang Y, Tang Z, Xue R, Singh GK, Lv Y, Shi K, Cai K, Deng L, Yang L (2011) TGF- $\beta 1$ promoted MMP-2 mediated wound healing of anterior cruciate ligament fibroblasts through NF- $\kappa \mathrm{B}$. Connect Tissue Res 52:218-225

42. Steadman JR, Feagin JA Jr (2008) The healing response technique: a minimally invasive procedure to stimulate healing of anterior cruciate ligament injuries using the microfracture technique. In: The crucial principles in care of the knee. Lippincott Williams \& Wilkins, pp 153-161. ISBN-10: 0-7817-7250-8

43. Steadman JR, Cameron-Donaldson ML, Briggs KK, Rodkey WG (2006) A minimally invasive technique ("Healing Response") to treat proximal ACL injuries in skeletally immature athletes. J Knee Surg 19:8-13

44. Steinwachs MR, Guggi T, Kreuz PC (2008) Marrow stimulation techniques. Injury 39(Suppl 1):S26-S31

45. Stengel D, Klufmöller F, Rademacher G, Mutze S, Bauwens K, Butenschön K, Seifert J, Wich M, Ekkernkamp A (2009) Functional outcomes and health-related quality of life after robotassisted anterior cruciate ligament reconstruction with patellar tendon grafts. Knee Surg Sports Traumatol Arthrosc 17:446-455

46. Streich NA, Barié A, Gotterbarm T, Keil M, Schmitt H (2010) Transphyseal reconstruction of the anterior cruciate ligament in prepubescent athletes. Knee Surg Sports Traumatol Arthrosc 18:1481-1486

47. Tapper JE, Funakoshi Y, Hariu M, Marchuk L, Thornton GM, Ronsky JL, Zernicke R, Shrive NG, Frank CB (2009) ACL/MCL transection affects knee ligament insertion distance of healing and intact ligaments during gait in the Ovine model. J Biomech 42:1825-1833

48. Voigt C, Schönaich M, Lill H (2006) Anterior cruciate ligament reconstruction: state of the art. Eur J Trauma 32:332-339

49. West RV, Harner CD (2005) Graft selection in anterior cruciate ligament reconstruction. J Am Acad Orthop Surg 13:197-207

50. Woo SL, Vogrin TM, Abramowitch SD (2000) Healing and repair of ligament injuries in the knee. J Am Acad Orthop Surg $8: 364-372$

51. Woods GA, Indelicato PA, Prevot TJ (1991) The Gore-Tex anterior cruciate ligament prosthesis: two versus three year results. Am J Sports Med 19:48-55 